\title{
Research on the Construction of Flexible Autonomous Learning Chain for Courses of Software Development
}

\author{
Li Yongjun ${ }^{\mathrm{a},}$, Jia Xiaohuib \\ Software College, Zhongyuan University of Technology, Zhongyuan Road 146, Zhongyuan District \\ of Zheng Zhou City, Henan Provice, China \\ ayongjunli@zut.edu.cn, bhui_jia@163.com
}

Keywords: Flexible Autonomous Learning Chain, Study Resource Library, Teaching Resource Library, Knowledge Library, Evaluation System

Abstract: With the development of Internet and teaching ideas such as micro class and flipped classroom are accepted gradually, many researchers and teachers are thinking about how to make students to learn knowledge actively in their spare time. A flexible autonomous learning chain is constructed which is an effective way to improve students' learning efficiency. According to the characteristics of the students and software development courses, principle and scheme of flexible autonomous learning chain are proposed, at the same time construction and application of the flexible autonomous learning chain in the course of "smart phone development" is made as an example. Practice has proved that the construction of flexible autonomous learning chain indeed improve the students' learning effects and benefits.

\section{Introduction}

Under the impact of emerging technologies such as information technology, big data, cloud computing and mobile internet, there arisen some new features of student's learning environment and characteristics such as learning time fragmentation, learning resources diversification, learning to focus on decentralization and so on. These new features have a great influence on the traditional classroom teaching. The traditional teaching activities such as classroom teaching and experiment can not stimulate learners' willingness to learn and reduce the impact on learning benefit gradually. With the emergence of MOOC, SPOC and other forms of teaching, the new teaching idea such as micro class, flipped classroom and so on goes deep into people's heart gradually and comes into the classroom. At the moment, the flexible learning way highlights its application value.

At present, most of the studies focused on the teaching of teachers, while the study of students is relatively little, especially in colleges and universities, the problem is more outstanding. On the one hand, university teachers have scientific research task, they must put a lot of time and energy in scientific research, leading to fewer inputs of thinking about teaching. On the other hand, college students too many and each student has different personality and basis, so common and rule is hard to find. The ultimate goal of teaching is to benefit students, which is reflected on the student's learning effect. How to improve students' learning effect and learning gains, not only the level of teachers' should be considered, but also the enthusiasm of students should be improved. At the same time, we should enrich the learning sources and custom all kinds of learn resources, so that students can choose it according to their own learning and acceptance. Moreover communication 
between students' learning and teachers' teaching is important, which is learning's interactivity. The current students have more than one device (e.g. mobile phone, computers, pad, etc), so there is no problem to exchange the sound source, picture, text between teachers and students and it is the most convenient and effective way to learn in the internet.

We all know that some "food chain" fracture will lead to the extinction of some species in the nature. Similarly, in the field of learning, if you don't follow the rule of learning and establish scientific autonomous learning chain, you will have difficult to achieve the desired learning effect. For example, the software development courses in college due to its own characteristics such as hard to entry, logicality, plus students have different basis and lack of motivation, the learning effect doesn't satisfied the teacher anticipated target. So it is particularly important to construct a flexible autonomous learning chain for software development course.

Build flexible chain of autonomous learning process is essentially a qualitative change of the learning process, which is from disorder to order, from shallow to deep, from bits and pieces scatted to mastery. Its aim is to optimize the process of teacher's "teaching" to the student's "learning".

\section{Principle of Flexible Autonomous Learning Chain}

"Autonomous learning" is a learning way for students to get scientific knowledge through self-study, exploration, and discovery. Students' main work is to learn, and they are the main body of learning, so they can arrange the whole process of learning, guided by a clear purpose and direction to conscientiously study, automatically and effectively study. Autonomous learning can cultivate the students' ability of active development, formed the good study quality, cultivate the students' confidence, stimulate students curiosity, etc.

"Flexible teaching" is an agile way to deliver the knowledge to the students and carry out teaching activities so that the learners can use a more elastic way to learn. On the one hand, requirements of diversification and inclusiveness are meet when teachers construct the system of talents training and the content of specialty course, on the other hand, learners can be autonomous learning according to their own ability of independent thinking, capability of innovation, learning methods and other personalized features. Flexible teaching helps to bring about students' learning internalization through a series of rules and methods, which can enhance learning and improve learning efficiency. So we should follow the following principles to build flexible learning chain:

First, meet students learning cognitive rule: from easy to difficult, go forward one by of knowledge, with practical example throughout the whole procedure;

Second, learning module is "pluggable": every learning module should be relatively independent and complete, when you have learned the simple module, you can choose the more difficult modules to continue to learn or switch to another new knowledge module to start;

Third, maximum participation is done through the whole process: students can apply for participation the design, implement for each knowledge point and evaluate it, or mutual evaluation between students;

Fourth, content is rich, and form is multiple: there are so many study sources, such as book itself and so many references, which can be used by PPT, word, prize etc. The case can be the most familiar knowledge of the comprehensive application and the professional APP;

Fifth, learning process can be recorded: we can count and analysis through third-party platform for Q\&A, homework correcting, learning effect, learning rule;

Sixth, a variety of convenient interaction between teachers and students: the students' question can by solved anytime, anywhere combined with the relevant communication tools, such as QQ group, We Chat group, e-mail and so on. 


\section{Scheme of Flexible Autonomous Learning Chain}

The construction of flexible autonomous learning chain affects the teaching design directly. Scheme is constructed according to experienced teachers in the course group, and the flexible autonomous learning chain scheme is contained five points:

First, flexible multi-objective learning plan is designed. There are three degrees named as basis compulsory, advanced elective, senior elective according to students' level, students' foundation, and individual differences of students', which are for the goal of initial programmer, intermediate programmers and senior programmers. And in each goal corresponding content is designed hierarchically.

Second, a complete set of "learning resource library" is built. The "learning resource library" should be created for students who have different level according to different learning stage in a course.

Third, corresponding "teaching resource library" is built. The teachers should build some teaching design, teaching lectures, teaching notes, teaching reflection and other construction combined with multi-objective learning program and individual different students to provide different groups of students with private libraries, public libraries and document database.

Forth, a reasonable "evaluation system program" is built. Evaluation system is no longer a single thing that is simply depended on the only one test finally, nor the traditional method which is divided into the usual results and final test results. It is created based on the initial level of students to develop different assessment criteria and the corresponding quantitative and qualitative assessment, and it is no longer one standard for the whole class. There are different test goal along with different students' study goal, different weight for different study goal is set. So students can get different score because they select a different study goal.

Fifth, a variety of exercises warehouse is built. We should give an exercises warehouse which is include blank filling question, true-false question, multiple-choice question and all kinds of question about program for students. We also can look for some good production from students every year and put them fill in the exercises warehouse so every student can know their own level and know how to do later.

\section{Application of Flexible Autonomous Learning Chain}

"Smart phone application development" is mainly to explain the current emerging technology Android which requiring handling ability and strong practicing as a software development courses. This course is planed for the students of two-year College, three-year College, four-year general undergraduate, and four-year outstanding classes. The professional direction is focused on mobile application development and network software development and so on. Students have different basis, some one only have Java basic grammar knowledge, some one have a certain object-oriented thinking, and some one have learned Java series courses. "Smart phone application development" not only includes the basic knowledge of Java, such as environment building, graphical user interface, common controls, layout, event response and so, it also includes some advanced applications such as multithreading, multimedia development, networking and communication, map, sensors and so on.

According to the principle and scheme of flexible autonomous learning chain, the flexible autonomous learning chain of this course is constructed which includes four modules as teaching resource library, learning resource library, knowledge library and evaluation system library. Teaching resource library and learning resource library are built on the basis knowledge and the knowledge content is used to evaluate for student achievement based on evaluation system which is composed of evaluation factors. With different weights, three evaluation systems are developed and 
evaluation factor is set according the characteristics of curriculum and content of knowledge points which is the basis of a study to conduct a comprehensive assessment of student. Knowledge content is divided into three levels which includes basic, advanced and senior. Basic is the foundation of advanced knowledge using solid arrows, and advanced is relatively independent and complete knowledge which has a week relation of senior, using dashed arrows. Flexible autonomous learning chain is shown in Figure 1.

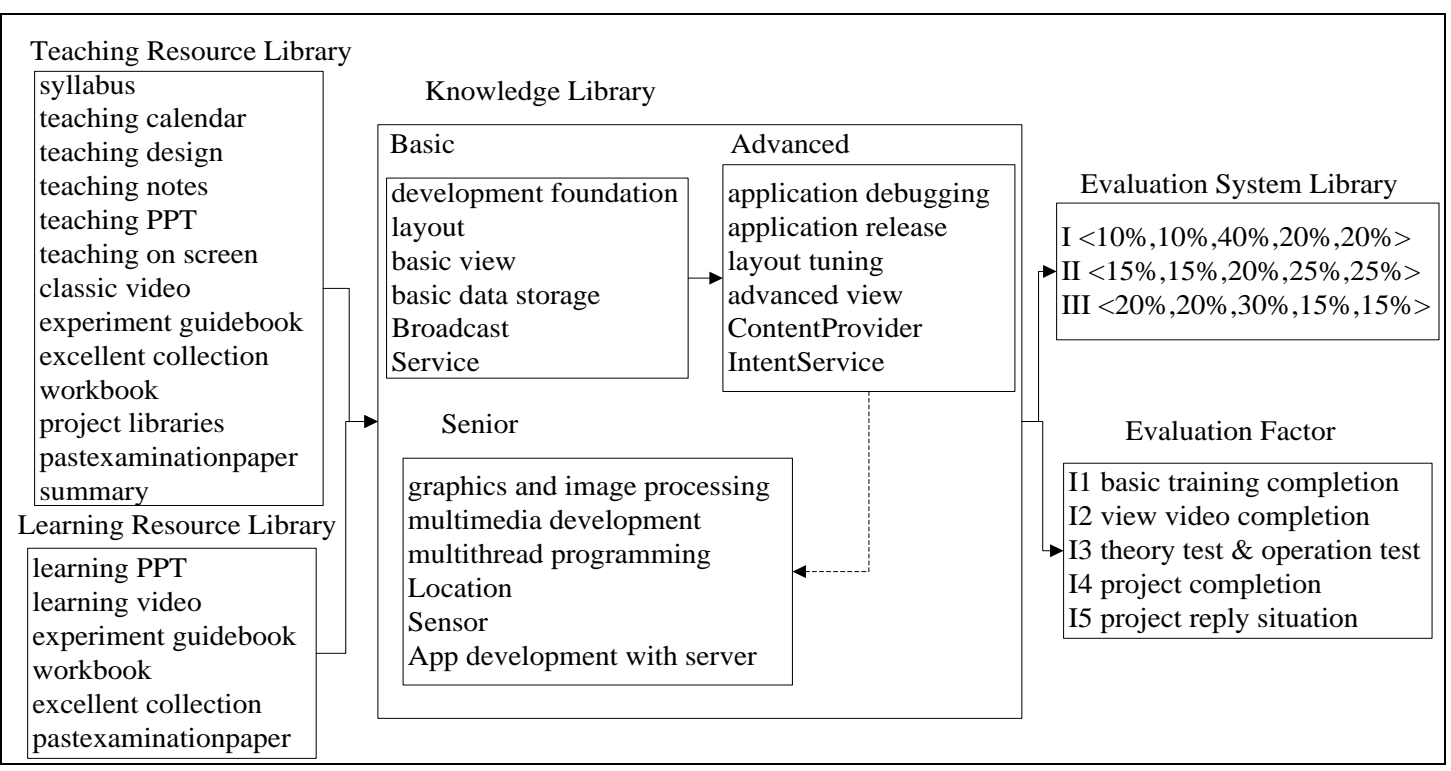

Figure 1 Flexible autonomous learning chain of "smart phone application development".

PPT, video, experiment guidebook, workbook, past-examination-paper are contained commonly in the teaching resource database and learning resource base, and the excellent collection in learning resource library is a subset of the teaching resource library, which is selected by teacher based on the students learning. Syllabus, teaching calendar, teaching design, teaching notes and other resources in the teaching resource database are serviced mainly for teachers, who can give a class using these resources and can meet the teaching requirements whether or not he has held the course before.

Syllabus, teaching calendar, teaching design, teaching notes, teaching PPT, experimental guidebook were planned for different professional direction. Workbook and project libraries were summarized and arranged and divided into different difficulty degree by teacher based on the current industry applications, student learning situation and so. Summary is concluded and proposed teaching recommendations according to students' performance and knowledge acceptance and other aspects in every class lectures. Past-examination-paper is collected based on different grades, different professional direction.

Knowledge classification is the first task when building the learning chain, followed by the division of difficulty based on industry and the student situation. Basic part is mainly on Android environment configuration, layout, view, four components and basic data storage. Advanced part is expanded for difficulties of basic part, such as ContentProvider of data storage, and IntentService of Service which is one of the four components. Senior part mainly aims at current employment enterprise needs and different application areas, including graphic images, multimedia, sensors and so on.

Evaluation factor mainly include basic training completion, view video completion on the third party platform, theory test and operation test completion and project reply situation of 2-3 students cooperation projects in view of the characteristics of course, while weights of every parts is 
assigned by teachers of one curriculum group.

The evaluation system is established with the idea of normal and comprehensive study, weakening test scores and strengthening usual grades, emphasizing theory and strong foundation. It is consisted of evaluation factors with different weights. And it conforms to the course and training objectives on one hand, on the other hand meets the characteristics of student learning.

\section{Effect of Flexible Autonomous Learning Chain construction}

The above principles of construction is followed by flexible learning chain construction, after the completion of learning chain construction, learning resource library is very rich, students can choose their own studying methods, such as watch online video, read documents, exercises to consolidate and so on. The enthusiasm and initiative of students to learn is inspired to a certain extent, and the classroom effect is improved. The basic content which has been mastered by students should be summarized and concise reviewed, and the knowledge which grasped weakly by students or extension of knowledge should be focused on in the classroom, and the construction of curriculum resources can adapt to the new teaching mode of Inverted Classroom. Through nearly two years of observation, student polarization is reduced and students collaborate on programming/learning has been improved more. The excellent and pass rate of final examination and excellent rate of basis, improved, comprehensive has been compared by using 2014, 2015 terms, whose major is software technology (mobile application development) which can be seen in Figure 2.

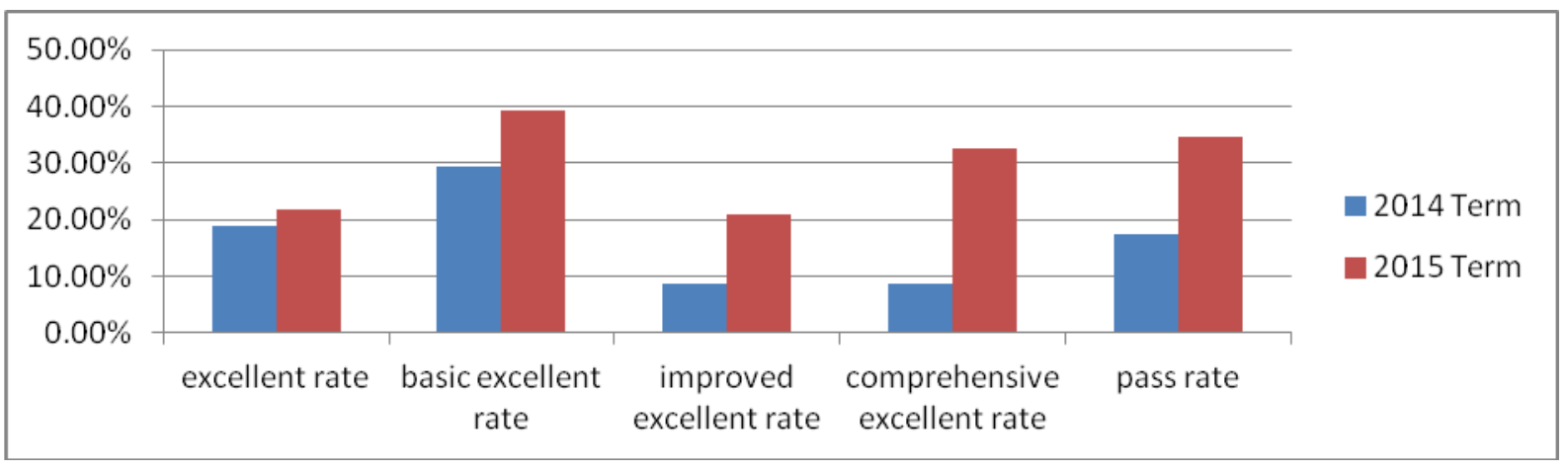

Figure 2 Comparison of final exam.

It can be clearly seen from the figure that the learning effect of the 2015 students has been improved in all aspects, especially in terms of excellent rate and pass rate, according to the above evaluation system, the learning resource library, the teaching resource library and the knowledge point library are constructed after adopted the flexible autonomous learning chain method.

\section{Conclusion}

Principles, schemes and effects of the construction of flexible autonomous learning chain were introduced in this paper and the flexible autonomous learning chain method is developed for "smart phone application development". By comparing the test scores of two terms, it can be seen that the flexible autonomous learning chain construction is very meaningful and is worth promoting in the current new learning environment. It is important to note that in the process of constructing of learning chain, how to determine the objectiveness of current individual differences for students has yet to be improved. 


\section{References}

[1] Zhao Qin.An Interpenetration of Autonomous Study Idea in the Computer Education in Universities.[J]. Theory and Practice of Education.2011,31(12):61-62.

[2] Wang Xiu-yan, Yang Yan-ci.Study on the Curriculum System based on the curriculum chain formed by project-a case study of computer software major.[J]. Journal of Hebei University of Engineering (Social Science Edition).2007,24(2):111-113.

[3] Yang Zhen, Wang Ai-ling. Factors Influencing Students' Effective Learning \& Approaches to Its Realization[J].Theory and Practice of Education.2016,36(10):56-59.

[4] Liu Zheng-xi, Wu Qian-hui. Cultivation of College Students' Learning Autonomy from the Perspective of “Flipped Classroom”[J]. Education Teaching Forum.2016,11(25):67-72.

[5] Wu Jin-zhou. Research and Practice on Teaching Reform for "Java programming” Course[J]. Education Teaching Forum.2016(45):93-95. 